\title{
Research Paper: The Effects of Changing Footstrike Pattern on the Amplitude and Frequency Spectrum of Ground Reaction Forces During Running in Indi- viduals With Pronated Feet
}

\author{
Arefeh Mokhtari Malekabadi ${ }^{1}$ (D), AmirAli Jafarnezhadgero" ${ }^{* *}$, Farshad Gghorbanlou $^{1}$ (D)
}

1. Department of Physical Education and Sport Sciences, Faculty of Educational Science and Psychology, University of Mohaghegh Ardabili, Ardabil, Iran.

\begin{tabular}{|c|c|}
\hline $\begin{array}{l}\text { Usue eourd device to scan } \\
\text { and read the article online }\end{array}$ & Citation Mokhtari Malekabadi A, Jafarnezhadgero AA, Gghorbanlou F. The Effects of Changing Footstrike Pattern on the \\
\hline 口ifig & Amplitude and Frequency Spectrum of Ground Reaction Forces During Running in Individuals With Pronated Feet. Physical \\
\hline Itrati & Treatments. 2020; 10(4):205-212. http://dx.doi.org/10.32598/ptj.10.4.348.2 \\
\hline 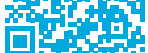 & doij: http://dx.doi.org/10.32598/ptj.10.4.348.2 \\
\hline
\end{tabular}

(i) (3)

Article info:

Received: 05 Dec 2019

Accepted: 01 Aug 2020

Available Online: 01 Oct 2020

Keywords:

Footstrike pattern,

Running, Pronated foot,

Ground reaction force

\section{A B S T RA C T}

Purpose: The current study aimed to evaluate the effects of barefoot and shod running with two different styles on ground reaction force-frequency content in recreational runners with low arched feet.

Methods: The statistical sample of this research was 13 males with Pronated Feet (PF) (Mean \pm SD age: $26.2 \pm 2.8 \mathrm{y}$; height: $176.1 \pm 8.4 \mathrm{~cm}$; weight: $78.3 \pm 14.3 \mathrm{~kg}$ ). A force plate (Bertec, USA) with a sample rate of $1000 \mathrm{~Hz}$ was used to record the reaction forces under each foot. Three test conditions in our study included shod running with rearfoot, midfoot, and forefoot patterns. Repeated-measures Analysis of Variance (ANOVA) was used for analyzing the data.

Results: During forefoot running, the research subjects attained 10\% higher GRF values in vertical direction, compared with rearfoot running $(\mathrm{P}<0.001, \mathrm{~d}=2.133)$. Forefoot running decreased the peak vertical GRF, compared to rearfoot running (by $12 \%, \mathrm{P}=0.01, \mathrm{~d}=0.826$ ). Barefoot running decreased the peak vertical GRF, compared to shod running (by $6 \%, \mathrm{P}=0.027$, $\mathrm{d}=1.143)$. The collected results revealed a significantly lower FyMed $(\mathrm{P}<0.02, \mathrm{~d}=1.11,14 \%)$, Fy99.5\% $(\mathrm{P}<0.02, \mathrm{~d}=0.11,8 \%)$, and greater FyNe $(\mathrm{P}<0.02, \mathrm{~d}=0.72,10 \%)$, Fz99.5\% $(\mathrm{P}<0.01$, $\mathrm{d}=4.30,124 \%)$, and $\mathrm{FzNe}(\mathrm{P}<0.01, \mathrm{~d}=1.65,44 \%)$ when running with rearfoot strike pattern, compared with forefoot strike pattern.

Conclusion: The study subjects with pronated feet experienced greater GRF values during forefoot running than rearfoot; such data may imply an increased risk of running injuries. Therefore, forefoot running is not recommended for runners with pronated feet.

\footnotetext{
* Corresponding Author:

AmirAli Jafarnezhadgero, $P h D$.

Address: Department of Physical Education and Sport Sciences, Faculty of Educational Science and Psychology, University of Mohaghegh Ardabili, Ardabil, Iran.

Phone: +98 (910) 5146214

E-mail: amiralijafarnezhad@gmail.com
} 


\section{Highlights}

- During forefoot running, the research subjects attained 10\% higher GRF values in the vertical direction, compared to rearfoot running.

- Forefoot running decreased the peak vertical GRF, compared to rearfoot running.

- Barefoot running decreased the peak vertical GRF, compared to shod running.

- Pair-wise comparisons revealed a significantly lower FyMed, Fy99.5\%, and greater FyNe, Fz99.5\%, and FzNe when running with the rearfoot strike, compared with forefoot strike methods.

\section{Plain Language Summary}

The study subjects with pronated feet experienced greater loads values during forefoot running than rearfoot, which may imply an increased risk of running injuries. Therefore, forefoot running is not recommended for runners with pronated feet.

\section{Introduction}

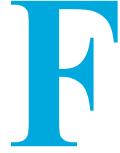

ootstrike type is related to how the plantar section of the foot hits the ground. There are 2 main kinds of footstrike methods, i.e., usually used by individuals. These methods are named rear-foot and fore-foot strike [1]. Previous studies have defined these approaches as mid-foot or fore-foot methods $[1,2]$. Limited research data proposed that individuals could benefit from changing their running strike methods. One important remaining data gap is understating which footstrike pattern could decrease the risk of injury.

Literature suggests that differences in running biomechanics arise due to different footstrike patterns. For example, some researchers reported that forefoot running may decrease shine splint [3]. Diebal et al. (2012) argued that the fore-foot method could reduce pain in runners [4]. The lack of the first peak in the vertical direction of Ground Reaction Force (GRF) and lower Loading Rates (LRs) during forefoot running may have implications for pain reduction and injury prevention in runners with patellofemoral pain syndrome [5]. However, extensive evidence suggests using rearfoot striking during running. For instance, Laughton et al. reported that rearfoot running could decrease the peak GRF values in vertical and anteroposterior directions; accordingly, it results in a decreased risk of running injury [6].

Furthermore, there are controversial findings of the effects of footwear on running biomechanics. Previous re- search studies indicated that shod running may decrease the injury risk in the lower extremities by attenuating vertical LR [7, 8]. Nevertheless, other researchers have reported a reduction in GRF components with instructed barefoot running $[9,10]$.

Excessive foot pronation is considered a major contributing factor to lower extremity injuries [11-13]. Foot pronation and tibia internal rotation are coupled with each other and may produce torsional forces [14, 15]. This torsional stress may lead to an associated ligament tear or avulsion fracture [16]. During walking, excessive foot pronation may result in an increased GRF [11] There exists a positive correlation between greater GRF amplitudes and lower limb injuries $[12,17]$. Controversial results have been reported concerning the influence of over-pronated feet on GRF magnitudes while running in individuals with Pronated Feet (PF). In particular, possible changes in the ground reaction force-frequency content of running remain unclear.

Ground reaction forces frequency analysis was used for the normal and pathological evaluation of walking in the study subjects [18]. Frequency content of GRF helps demonstrate the magnitude and effects of anatomical structures in a frequency content analysis [19]. Frequency content has been demonstrated to be a clinically essential factor in introducing running-related injuries in individuals with excessive foot pronation. The frequency of GRF during daily living activities plays a major role in clinical treatments [20]. 
Despite numerous studies on running, research about the relationship between GRF components and excessive foot pronation are scarce. The present research aimed to assess the effects of barefoot and shod running with two different styles on ground reaction force-frequency content in recreational runners with PF.

\section{Materials and Methods}

The statistical sample of this study was 13 males with PF (Mean \pm SD age: $26.2 \pm 2.8 \mathrm{y}$; height: $176.1 \pm 8.4 \mathrm{~cm}$; weight: $78.3 \pm 14.3 \mathrm{~kg}$ ). A written informed consent form was received from the research subjects. The exclusion criteria of the study have presented the signs of joint disease, bone disease, ligament injury, musculoskeletal disorders, tendon diseases, a history of severe trauma or lower limb surgery, chronic infections of the joint, and corticosteroid injection. The dominant lower limb of all study subjects was determined by a soccer ball shoot test.

Gender-wise biomechanical differences were identified; such differences occur in several directions and along multiple joints [21]. The Ethics Committee of Ardabil University of Medical Scinces research protocol (Code: IR.ARUMS.REC.1398.408).

A force plate (Bertec, USA) was used to record the GRF components at the sample rate of $1000 \mathrm{~Hz}$. A 20 $\mathrm{Hz}$ cut-off frequency was used to filter GRF data. Heel contact and toe-off were determined as the first point $>20$ $\mathrm{N}$ and toe off as the last point $>20 \mathrm{~N}$, respectively [13].

The study participants run at $3.3 \mathrm{~m} / \mathrm{s}$ on a force plate on a runway with an $18 \mathrm{~m}$ length. Three running trials were performed for the familiarization process. Data collection was conducted during shod and barefoot running with rearfoot and forefoot patterns. A randomized method was used to determine the order of running conditions. Three running trials with a 2-min rest were performed between each condition. A true trial was defined if the plantar section of the foot was placed on the center of the force plate.

Concerning the ground reaction force-frequency spectrum analysis, three directions of GRF (Fx, Fy, Fz) were used for Fourier analysis. Fourier method, as defined and presented below, was conducted on the GRF data. MATLAB software was applied to compute the frequency spectrum of the GRF [22]. The other details for computing the Fourier series of GRF are described in the literature [23]. Five indexes of frequency-domain were computed and used in the statistical section [23, 24]. The frequency with a power of $99.5 \%$ (F99.5\%) was the first used index (Equation 1) [24]. The median frequency (Fmed) of GRF was calculated as the second index [24]. The median frequency can demonstrate the functions of swinging parts of neuromotor sections at the heel-contact phase [24, 25]. Frequency bandwidth (F-band) was the third index, i.e., the range of frequency where power spectrum density is greater than half of the peak value [24].

$$
\text { 1: } \int_{0}^{f 99.5} P(f) d f=0.995 \times \int_{0}^{f \max } P(f) d f
$$

$\mathrm{P}$ is the integral power of frequency, Fmax is the highest frequency of the curve, and $\mathrm{P}(\mathrm{f})$ is defined as the power at frequency $\mathrm{f}[24]$. The essential number of harmonics (ne) is the fourth index needed for $99.5 \%$ confidence of data to reconstruct [26].

$$
\text { 2: } \sum_{n=1}^{n e} \frac{\sqrt{A_{n}^{2}+B_{n}^{2}}}{\sum_{n=1}^{m} \sqrt{A_{n}^{2}+B_{n}^{2}}} \leq 0.995
$$

Here, "n" is the number of harmonics; An and Bn are the coefficients of the Fourier equation (Equation 2). The amplitude of each harmonic (Hi) is the fifth index, where " $\mathrm{i}$ " is the harmonic number.

Shapiro-Wilk test was used for establishing the normal distribution of the collected data. Repeated-measures Analysis of Variance (ANOVA) was used for statistical analysis. Cohen's ds was also computed [22] and interpreted in the statistical section [23]. The significant level was set at $\mathrm{P}<0.05$. The data analyzedsis SPSS was applied for statistical of the obtained.

\section{Results}

Table 1 describes the effects of "footstrike pattern" and "footwear" conditions on GRF time series data. Significant main effects of "footstrike pattern" were observed for vertical GRF (Fz) and loading rate. During forefoot running, the research subjects attained 10\% higher GRF values in the vertical direction, in comparison with rearfoot running $(\mathrm{P}<0.001, \mathrm{~d}=2.133)$. Forefoot running decreased the peak vertical GRF, compared to rearfoot running (by $12 \%, \mathrm{P}=0.01, \mathrm{~d}=0.826$ ). Figure 1 illustrates the patterns of GRF in all directions for the tested running conditions.

Furthermore, a significant main effect of shoes was observed in the peak vertical GRF. Barefoot running decreased the vertical GRF peal value, compared to shod running (by $6 \%, \mathrm{P}=0.027, \mathrm{~d}=1.143$ ). The statistical analysis presented significant footstrike by footwear interactions for vertical GRF ( $\mathrm{P}=0.001, \mathrm{~d}=2.409$ ). 
Table 1. The effects of footstrike pattern and footwear on GRF components during running

\begin{tabular}{|c|c|c|c|c|c|c|c|}
\hline \multirow{3}{*}{ Variables } & \multicolumn{7}{|c|}{ No. (\%) } \\
\hline & \multicolumn{2}{|c|}{ Barefoot } & \multicolumn{2}{|c|}{ Shod } & \multicolumn{3}{|c|}{ P (effect size: d) } \\
\hline & Rearfoot & Forefoot & Rearfoot & Forefoot & $\begin{array}{c}\text { Main Effect: } \\
\text { Footstrike Pattern }\end{array}$ & $\begin{array}{l}\text { Main Effect: } \\
\text { Footwear }\end{array}$ & $\begin{array}{c}\text { Interaction: } \\
\text { Footstrike } \times \text { Footwear }\end{array}$ \\
\hline $\mathrm{Fz}$ & $229.1(23.2)$ & 270.8 (19.6) & $234.4(9.1)$ & 237.5 (11.6) & $0.000(2.133)$ & $0.027(1.143)$ & $0.001(2.409)$ \\
\hline Fy (Braking) & $37.3(9.2)$ & 36.4 (8.9) & 33.2 (8.7) & 40.4 (8.7) & $0.973(0.045)$ & $170(0.843)$ & $0.264(0.678)$ \\
\hline Fy (Propulsion) & $27.2(9.8)$ & $26.1(8.8)$ & $28.6(6.5)$ & $29.8(8.6)$ & $0.187(0.807)$ & $0.615(0.300)$ & $0.985(0.045)$ \\
\hline Fx (Lateral) & 9.9 (4.16) & $11.8(3.4)$ & 10.4 (4.5) & $8.9(4.3)$ & 0.277 (0.659) & $0.170(0.843)$ & $0.899(0.063)$ \\
\hline Fx (Medial) & $6.8(3.3)$ & $7.8(3.2)$ & $8.4(3.9)$ & $8.8(4.5)$ & 0.177 (0.827) & $0.796(0.155)$ & $0.435(0.052)$ \\
\hline Loading rate & $89.4(11.8)$ & $71.4(15.6)$ & $72.8(24.8)$ & $68.1(15.1)$ & $0.010(0.826)$ & $0.064(0.672)$ & $0.288(0.640)$ \\
\hline
\end{tabular}

Table 2 lists the effects of footstrike pattern and footwear conditions on GRF frequency contents. Significant main effects of footstrike for FyMed, Fy99.5\%, FyNe, Fz99.5\%, and FzNe $(\mathrm{P}<0.02, \mathrm{~d}=1.566-9.798)$ were observed. A significantly lower FyMed $(\mathrm{P}<0.02, \mathrm{~d}=1.11$, $14 \%)$, Fy99.5\% $(\mathrm{P}<0.02, \mathrm{~d}=0.11,8 \%)$, and greater FyNe $(\mathrm{P}<0.02, \quad \mathrm{~d}=0.72, \quad 10 \%), \quad \mathrm{Fz} 99.5 \% \quad(\mathrm{P}<0.01, \quad \mathrm{~d}=4.30$, $124 \%)$, and FzNe $(\mathrm{P}<0.01, \mathrm{~d}=1.65,44 \%)$ values were detected when running with rearfoot, compared with forefoot conditions. Moreover, significant main effects of footwear for FyNe and FzNe $(\mathrm{P}<0.01, \mathrm{~d}=2.35-3.289)$ were reported. A significantly lower FyNe $(\mathrm{P}<0.01$, $\mathrm{d}=1.64,30 \%)$ and greater FzNe $(\mathrm{P}<0.01, \mathrm{~d}=1.21,31 \%)$ during barefoot running were observed, compared with shod running. Besides, significant interaction effects of footstrike $\times$ footwear for FxNe $(\mathrm{P}=0.03, \mathrm{~d}=1.341), \mathrm{FyNe}$ $(\mathrm{P}=0.01, \mathrm{~d}=1.667)$, and FzNe $(\mathrm{P}<0.001, \mathrm{~d}=2.167)$ were demonstrated.
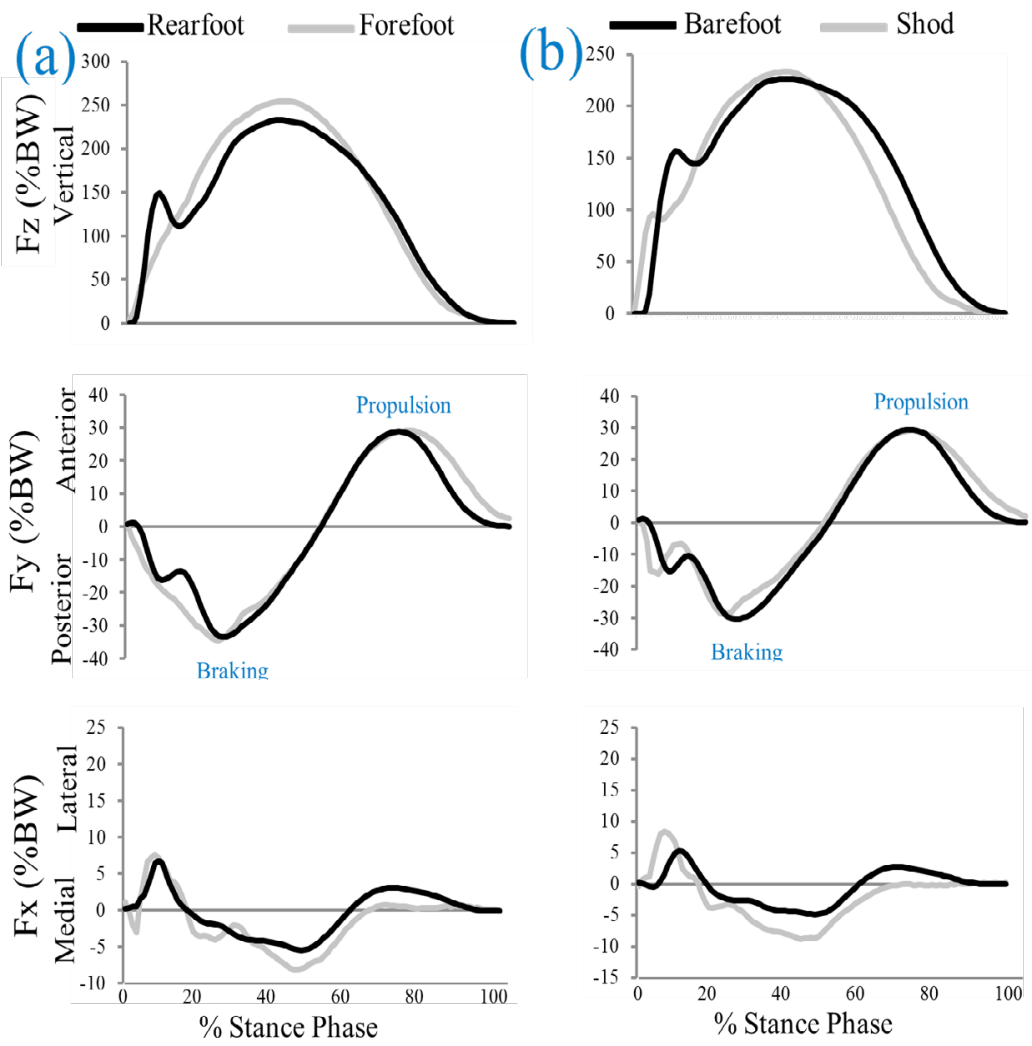

PHYSICAL TREA $\mid$ MENTS

Figure 1. Time-series curve of the ground reaction forces for footstrike pattern (a) and footwear (b) conditions while running 
Table 2. The effects of footstrike pattern and footwear on GRF frequency contents during running

\begin{tabular}{|c|c|c|c|c|c|c|c|}
\hline \multirow{3}{*}{ Variables } & \multicolumn{4}{|c|}{ Mean $\pm S D$} & \multicolumn{3}{|c|}{ No. (\%) } \\
\hline & \multicolumn{2}{|c|}{ Barefoot } & \multicolumn{2}{|c|}{ Shod } & \multirow{2}{*}{$\begin{array}{c}\text { Main Effect: } \\
\text { Footstrike Pattern }\end{array}$} & \multirow{2}{*}{$\begin{array}{l}\text { Main Effect: } \\
\text { Footwear }\end{array}$} & \multirow{2}{*}{$\begin{array}{c}\text { Interaction: } \\
\text { FootstrikexFootwear }\end{array}$} \\
\hline & Rearfoot & Forefoot & Rearfoot & Forefoot & & & \\
\hline FxBand & $1.08 \pm 0.27$ & $1.08 \pm 0.27$ & $1.08 \pm 0.27$ & $1.00 \pm 0.00$ & $0.58(0.286)$ & $0.58(0.286)$ & $0.58(0.286)$ \\
\hline FxMed & $2.15 \pm 0.55$ & $2.15 \pm 0.55$ & $2.15 \pm 0.37$ & $1.92 \pm 0.27$ & 0.05 (1.702) & $0.42(0.459)$ & $0.33(0.549)$ \\
\hline $\mathrm{Fx}$ & & & & & & & \\
\hline Fx99.5\% & $11.31 \pm 2.72$ & $10.85 \pm 2.85$ & $12.08 \pm 2.32$ & $10.00 \pm 1.35$ & $0.19(0.773)$ & $0.23(0.703)$ & $0.92(0.00)$ \\
\hline $\mathrm{FxNe}$ & $27.31 \pm 4.34$ & $25.62 \pm 5.48$ & $24.69 \pm 5.73$ & $22.00 \pm 7.28$ & $0.13(0.905)$ & $0.80(0.00)$ & $0.03(1.341)$ \\
\hline FyBand & $1.00(0.00)$ & $1.00(0.00)$ & $1.00(0.00)$ & $1.00(0.00)$ & $1.00(0.00)$ & $1.00(0.00)$ & $1.00(0.00)$ \\
\hline FyMed & $1.77 \pm 0.43$ & $1.85 \pm 0.37$ & $1.38 \pm 0.50$ & $1.85 \pm 0.38$ & $0.01(1.667)$ & $0.09(1.301)$ & $0.09(1.301)$ \\
\hline $\mathrm{Fz}$ & & & & & & & \\
\hline Fy99.5\% & $9.38 \pm 1.50$ & $10.85 \pm 1.34$ & $9.31 \pm 1.60$ & $9.62 \pm 1.04$ & $0.01(1.566)$ & $0.15(0.840)$ & $0.09(1.301)$ \\
\hline FyNe & $26.15 \pm 5.75$ & $20.23 \pm 7.29$ & $30.08 \pm 5.48$ & $30.46 \pm 2.22$ & $0.01(1.566)$ & 0.00 (3.289) & $0.01(1.667)$ \\
\hline FzBand & $1.00 \pm 0.00$ & $1.00 \pm 0.00$ & $1.00 \pm 0.00$ & $1.00 \pm 0.00$ & $1.00(0.00)$ & $1.00(0.00)$ & $1.00(0.00)$ \\
\hline FzMed & $2.00 \pm 0.00$ & $2.00 \pm 0.00$ & $2.00 \pm 0.00$ & $1.92 \pm 0.27$ & $0.33(0.549)$ & $0.33(0.549)$ & $0.33(0.549)$ \\
\hline $\mathrm{Fz}$ & & & & & & & \\
\hline Fz99.5\% & $8.77 \pm 1.30$ & $3.69 \pm 0.48$ & $8.00 \pm 1.00$ & $3.77 \pm 0.59$ & $0.00(9.798)$ & 0.07 (1.093) & $0.17(0.807)$ \\
\hline $\mathrm{FzNe}$ & $18.08 \pm 6.17$ & $10.54 \pm 1.89$ & $11.69 \pm 1.79$ & $10.00 \pm 1.58$ & 0.00 (3.289) & $0.00(2.35)$ & $0.00(2.167)$ \\
\hline
\end{tabular}

\section{Discussion}

The current research aimed to assess the influence of barefoot and shod running with two styles on ground reaction force-frequency content in recreational runners with pronated feet. Our study data revealed that forefoot running increases peak vertical GRF. These results are consistent with those of the previous studies in runners [27, 28]. Daoud et al. (2012) argued that runners with forefoot strikes face fewer running-induced injuries, compared to those with rearfoot strikes [29]. Besides, transitioning to a forefoot strike method has been suggested to improve injuries, including chronic exertional compartment [29] and patellofemoral pain syndromes [5]. The data indicated that peak vertical GRF was higher during forefoot running than rearfoot running. Literature suggested that increased GRF is related to a greater risk of lower limb injuries $[6,28,30]$.

Greater GRF during running could lead to an increased risk of ACL tear [31]. The impact forces transferred to the body in subjects with pronated feet are greater than those in healthy controls [32]. In the present study subjects with PF experienced higher GRF values during forefoot running, compared to the rearfoot condition; it may imply an increased risk of running injuries. Therefore, forefoot running is not recommended for runners with PF.

In forefoot running, a significantly lower vertical loading rate was found, agreeing with the results of previous studies $[5,33]$. The impact of body weight in the vertical section resulted in discrepancies between directions (GRF: vertical $>$ anterior-posterior $>$ medio-lateral) [22]. The absent or reduced impact peak in vertical GRF during forefoot running may lead to decreased vertical load rates, compared with the rearfoot running footfall pattern (Figure 1.a). Reduced impact peak during forefoot running may reduce running-related injuries [20].

The greater loading rates at rearfoot running may be due to higher vertical displacement [34], or higher joint stiffness [35], or both [36]. Greater vertical displacement of the runner's center of gravity may adversely affect running economy. However, there was no significant difference in running economy between different running strike approaches [37].

The present study findings indicated that barefoot running decreased the peak vertical GRF, compared to shod running. In line with this finding, previous studies have reported reduced peak GRF values during barefoot in 
healthy runners $[38,39]$. The characteristics of the vertical GRF during the first half of running gait depend upon the initial condition of the lower limb joints at touchdown [40]. During barefoot running, the ankle is in a more plantar-flexed position before initial contact and the knee becomes significantly more flexed before initial contact [8].

These kinematic characteristics may alter the kinetic forces at the lower limb and induce an adaptation strategy to barefoot running. Furthermore, the observed results may be because our subjects had PF; this condition may cause biomechanical changes on the lower limb joints during running [22]. Thus, individuals with overpronated feet may be more exposed to chronic knee and hip osteoarthritis. Our research findings suggested that the footwear could affect the GRF values; consequently, it impacts the loads applied to the lower extremity during running in individuals with PF. The median frequency in the anterior-posterior direction was declined in the rearfoot pattern, compared to the forefoot pattern during running with and without shoes.

The limitations of this research included a lack of kinematic data, as well as the lack of electromyography data and joint stiffness data.

\section{Conclusion}

The study subjects with pronated feet experienced greater GRF values during forefoot running than rearfoot; such data may imply an increased risk of running injuries. Therefore, forefoot running is not recommended for runners with pronated feet.

\section{Ethical Considerations}

\section{Compliance with ethical guidelines}

The Ethics Committee of Ardabil University of Medical Scinces research protocol (Code: IR.ARUMS. REC.1398.408).

\section{Funding}

This research did not receive any grant from funding agencies in the public, commercial, or non-profit sectors.

\section{Authors' contributions}

All authors equally contributed to preparing this article.

\section{Conflict of interest}

The authors declared no conflicts of interest

\section{References}

[1] Hamill J, Gruber AH. Is changing footstrike pattern beneficial to runners? Journal of Sport and Health Science. 2017 6(2):146-53. [DOI:10.1016/j.jshs.2017.02.004] [PMID] [PMCID]

[2] Ahn AN, Brayton C, Bhatia T, Martin P. Muscle activity and kinematics of forefoot and rearfoot strike runners. Journal of Sport and Health Science. 2014; 3(2):102-12. [DOI:10.1016/j. jshs.2014.03.007]

[3] Sasimontonkul S, Bay BK, Pavol MJ. Bone contact forces on the distal tibia during the stance phase of running. Journal of Biomechanics. 2007; 40(15):3503-9. [DOI:10.1016/j.jbiomech.2007.05.024] [PMID]

[4] Diebal AR, Gregory R, Alitz C, Gerber JP. Forefoot running improves pain and disability associated with chronic exertional compartment syndrome. The American Journal of Sports Medicine. 2012; 40(5):1060-7. [DOI:10.1177/0363546512439182] [PMID]

[5] Cheung RTH, Davis IS. Landing pattern modification to improve patellofemoral pain in runners: A case series. Journal of Orthopaedic \& Sports Physical Therapy. 2011; 41(12):9149. [DOI:10.2519/jospt.2011.3771] [PMID]

[6] Laughton CA, Davis IM, Hamill J. Effect of strike pattern and orthotic intervention on tibial shock during running. Journal of Applied Biomechanics. 2003; 19(2):153-68. [DOI:10.1123/ jab.19.2.153]

[7] Mei Q, Fernandez J, Fu W, Feng N, Gu Y. A comparative biomechanical analysis of habitually unshod and shod runners based on a foot morphological difference. Human Movement Science. 2015; 42:38-53. [DOI:10.1016/j.humov.2015.04.007] [PMID]

[8] De Wit B, De Clercq D, Aerts P. Biomechanical analysis of the stance phase during barefoot and shod running. Journal of Biomechanics. 2000; 33(3):269-78. [DOI:10.1016/S00219290(99)00192-X] [PMID]

[9] Samaan CD, Rainbow MJ, Davis IS. Reduction in ground reaction force variables with instructed barefoot running. Journal of Sport and Health Science. 2014; 3(2):143-51 [DOI:10.1016/j.jshs.2014.03.006]

[10] Hollander K, Heidt C, Van der Zwaard BC, Braumann K-M, Zech A. Long-term effects of habitual barefoot running and walking: A systematic review. Medicine \& Science in Sports \& Exercise. 2017; 49(4):752-62. [DOI:10.1249/ MSS.0000000000001141] [PMID]

[11] Jafarnezhadgero A, Madadi-Shad M, Alavi-Mehr SM, Granacher $\mathrm{U}$. The long-term use of foot orthoses affects walking kinematics and kinetics of children with flexible flat feet: A randomized controlled trial. PloS One. 2018;13(10):e0205187. [DOI:10.1371/journal.pone.0205187] [PMID] [PMCID]

[12] Jafarnezhadgero AA, Oliveira AS, Mousavi SH, MadadiShad M. Combining valgus knee brace and lateral foot wedges reduces external forces and moments in osteoarthritis patients. Gait \& Posture. 2018; 59:104-10. [DOI:10.1016/j. gaitpost.2017.09.040] [PMID]

[13] Jafarnezhadgero A, Fatollahi A, Amirzadeh N, Siahkouhian M, Granacher U. Ground reaction forces and muscle activity while walking on sand versus stable ground in individuals with pronated feet compared with healthy con- 
trols. PloS One. 2019; 14(9):e0223219. [DOI:10.1371/journal. pone.0223219] [PMID] [PMCID]

[14] Jafarnezhadgero A, Shad MM, Ferber R. The effect of foot orthoses on joint moment asymmetry in male children with flexible flat feet. Journal of Bodywork and Movement Therapies. 2018; 22(1):83-9. [DOI:10.1016/j.jbmt.2017.04.007] [PMID]

[15] Okunuki T, Koshino Y, Yamanaka M, Tsutsumi K, Igarashi $\mathrm{M}$, Samukawa $\mathrm{M}$, et al. Forefoot and hindfoot kinematics in subjects with medial tibial stress syndrome during walking and running. Journal of Orthopaedic Research. 2019; 37(4):927-32. [DOI:10.1002/jor.24223] [PMID]

[16] McGoldrick NP, Murphy EP, Kearns SR. Single oblique incision for simultaneous open reduction and internal fixation of the posterior malleolus and anterior syndesmosis. The Journal of Foot and Ankle Surgery. 2016; 55(3):664-7. [DOI:10.1053/j.jfas.2016.01.031] [PMID]

[17] Dayakidis MK, Boudolos K. Ground reaction force data in functional ankle instability during two cutting movements. Clinical Biomechanics. 2006; 21(4):405-11. [DOI:10.1016/j. clinbiomech.2005.11.010] [PMID]

[18] Stergiou N, Giakas G, Byrne JB, Pomeroy V. Frequency domain characteristics of ground reaction forces during walking of young and elderly females. Clinical Biomechanics. 2002; 17(8):615-7. [DOI:10.1016/S0268-0033(02)00072-4]

[19] Wu J, Beerse M, Ajisafe T. Frequency domain analysis of ground reaction force in preadolescents with and without Down syndrome. Research in Developmental Disabilities. 2014; 35(6):1244-51. [DOI:10.1016/j.ridd.2014.03.019] [PMID]

[20] Gruber AH, Edwards WB, Hamill J, Derrick TR, Boyer KA. A comparison of the ground reaction force frequency content during rearfoot and non-rearfoot running patterns. Gait \& Posture. 2017; 56:54-59. [DOI:10.1016/j.gaitpost.2017.04.037] [PMID]

[21] Jenkins WL, Williams III DSB, Williams K, Hefner J, Welch H. Sex differences in total frontal plane knee movement and velocity during a functional single-leg landing. Physical Therapy in Sport. 2017; 24:1-6. [DOI:10.1016/j.ptsp.2016.09.005] [PMID]

[22] Winter DA. Biomechanics and motor control of human movement. $4^{\text {th }}$ edition. New Jersey: John Wiley \& Sons; 2009. [DOI:10.1002/9780470549148]

[23] Giakas G, Baltzopoulos V. Time and frequency domain analysis of ground reaction forces during walking: An investigation of variability and symmetry. Gait \& Posture. 1997; 5(3):189-97. [DOI:10.1016/S0966-6362(96)01083-1]

[24] McGrath D, Judkins TN, Pipinos II, Johanning JM, Myers SA. Peripheral arterial disease affects the frequency response of ground reaction forces during walking. Clinical Biomechanics. 2012; 27(10):1058-63. [DOI:10.1016/j.clinbiomech.2012.08.004] [PMID] [PMCID]

[25] Crowe A, Schiereck P, de Boer R, Keessen W. Characterization of gait of young adult females by means of body centre of mass oscillations derived from ground reaction forces. Gait \& Posture. 1993; 1(1):61-8. [DOI:10.1016/0966-6362(93)90043-Z]

[26] Schneider E, Chao EY. Fourier analysis of ground reaction forces in normals and patients with knee joint disease. Journal of Biomechanics. 1983; 16(8):591-601. [DOI:10.1016/00219290(83)90109-4]
[27] Rice HM, Jamison ST, Davis IS. Footwear matters: Influence of footwear and foot strike on load rates during running. Medicine and Science in Sports and Exercise. 2016; 48(12):2462-8. [DOI:10.1249/MSS.0000000000001030] [PMID]

[28] Lieberman DE, Venkadesan M, Werbel WA, Daoud AI D'andrea S, Davis IS, et al. Foot strike patterns and collision forces in habitually barefoot versus shod runners. Nature. 2010; 463(7280):531-5. [DOI:10.1038/nature08723] [PMID]

[29] Daoud AI, Geissler GJ, Wang F, Saretsky J, Daoud YA, Lieberman DE. Foot strike and injury rates in endurance runners: A retrospective study. Medicine and Science in Sports and Exercise. 2012; 44(7):1325-34. [DOI:10.1249/ MSS.0b013e3182465115] [PMID]

[30] Jafarnezhadgero AA, Majlesi M, Etemadi H, Hilfiker R, Knarr BA, Shad MM. Effect of 16-week corrective training program on three dimensional joint moments of the dominant and non-dominant lower limbs during gait in children with genu varus deformity. Science \& Sports. 2020; 35(1):44. e1-11. [DOI:10.1016/j.scispo.2018.12.011]

[31] McLean SG, Huang X, van den Bogert AJ. Association between lower extremity posture at contact and peak knee valgus moment during sidestepping: Implications for ACL injury. Clinical Biomechanics. 2005; 20(8):863-70. [DOI:10.1016/j.clinbiomech.2005.05.007] [PMID]

[32] Kendall JC, Bird AR, Azari MF. Foot posture, leg length discrepancy and low back pain--their relationship and clinical management using foot orthoses: An overview. Foot. 2014 24(2):75-80. [DOI:10.1016/j.foot.2014.03.004] [PMID]

[33] Yong JR, Silder A, Delp SL. Differences in muscle activity between natural forefoot and rearfoot strikers during running. Journal of Biomechanics. 2014; 47(15):3593-7. [DOI:10.1016/j.jbiomech.2014.10.015] [PMID] [PMCID]

[34] Hobara H, Inoue K, Gomi K, Sakamoto M, Muraoka T, Iso $\mathrm{S}$, et al. Continuous change in spring-mass characteristics during a $400 \mathrm{~m}$ sprint. Journal of Science and Medicine in Sport. 2010; 13(2):256-61. [DOI:10.1016/j.jsams.2009.02.002] [PMID]

[35] Hunter I. A new approach to modeling vertical stiffness in heel-toe distance runners. Journal of Sports Science \& Medicine. 2003; 2(4):139-43. [PMCID]

[36] An W, Rainbow MJ, Cheung RTH. Effects of surface inclination on the vertical loading rates and landing pattern during the first attempt of barefoot running in habitual shod runners. BioMed Research International. 2015; 2015:240153. [DOI:10.1155/2015/240153] [PMID] [PMCID]

[37] Perl DP, Daoud AI, Lieberman DE. Effects of footwear and strike type on running economy. Medicine and Science in Sports and Exercise. 2012; 44(7):1335-43. [DOI:10.1249/ MSS.0b013e318247989e] [PMID]

[38] Arnold BJW, Weeks BK, Horan SA. An examination of treadmill running familiarisation in barefoot and shod conditions in healthy men. Journal of Sports Sciences. 2019; 37(1):5-12. [DOI:10.1080/02640414.2018.1479533] [PMID]

[39] Vincent HK, Massengill C, Harris A, Chen C, Wasser JG, Bruner $\mathrm{M}$, et al. Cadence impact on cardiopulmonary, metabolic and biomechanical loading during downhill running. Gait \& Posture. 2019; 71:186-91. [DOI:10.1016/j.gaitpost.2019.04.022] [PMID] 
[40] Kulmala J-P, Avela J, Pasanen K, Parkkari J. Forefoot strikers exhibit lower running-induced knee loading than rearfoot strikers. Medicine and Science in Sports and Exercise. 2013; 45(12):2306-13. [DOI:10.1249/MSS.0b013e31829efcf7] [PMID 